\title{
COVID-19 AND MITIGATION STRATEGIES: THE IMPACTOUR PILOTS COMMUNITY PERSPECTIVE
}

\author{
Pedro Pereira \\ João Martins \\ Graham Bell \\ Tarmo Kalvet \\ Shabnam Pasandideh
}

https://doi.org//10.20867/tosee.06.40

\begin{abstract}
Purpose - The quest for sustainable cultural tourism is undoubtedly connected with local communities. This paper presents the approaches taken by IMPACTOUR Project Pilots Community members to overcome COVID- 19 issues.

Methodology - A conceptual framework for this research is applied. The data gathering for this paper followed a methodology based on surveys, webinars and workshops, inside the IMPACTOUR project pilots.

Findings - A common belief is that digital is the key to sustainable Cultural Tourism. Different solutions were reported, such as digitalization of museums' content, digital campaigns towards tourists, more and easily understandable digital information, digital events, or digital marketing. Several destinations suffered a considerable reduction in international mass tourism, but an increase of local and cross-border tourism was found as the "new normal". Also, the proposed Sustainability-Green-Digital triangle could be the key to unlock hidden treasures and move towards new and more sustainable Cultural Tourism business models.

Contribution-Based on our research, the results of this paper are applicable as a resilient strategy for Cultural Tourism Communities. The findings are a new approach, the sustainability-greendigital triangle, which can be seen as an instrument for decision and policymakers to boost their strategies and find best practices for any future unpredictable situation.
\end{abstract}

Keywords: Cultural Tourism, COVID-19, Resilience, Local Communities, IMPACTOUR.

\section{INTRODUCTION}

Cultural Heritage is a dynamic reference point and a positive instrument for growth and change, and nowadays, the natural and cultural heritage, diversities, and living cultures are the major tourism tourist attractions worldwide.

Cultural tourism (CT), as defined by (UNWTO 2017) is a type of tourism activity in which the visitor's essential motivation is to learn, discover, experience, and consume the tangible and intangible cultural attractions/products in a tourism destination. By Movaway from the initial elite customers' orientation, cultural tourism has developed toward the mass market, broadening its concept and comprising, apart from sites and monuments, creativity, lifestyles, traditions, and everyday culture. 
ToSEE - Tourism in Southern and Eastern Europe, Vol. 6, pp. 587-606, 2021.

P. Pereira, J. Martins, G. Bell, T. Kalvet, S. Pasandideh: COVID-19 AND MITIGATION STRATEGIES ...

At the European level, several initiatives promoting labels and prizes for increasing cultural tourism attractiveness and strengthening the European sense of belonging have emerged and are now recognized for their global impact.

Marketing strategies and destination branding are critical elements for cultural sites promotion and successful heritage programs. Benefits in being awarded a heritage label have resulted in -term effects, both economic and networking capacity.

Accordingly, sustainable cultural tourism policies and strategies can play pivotal roles in the economic and social development of European regions and urban areas. Uncertainty and crisis can happen due to natural disasters or disease pandemics like COVID-19 (declared pandemic by WHO, March 12, 2020), dramatically impacting tourist sector businesses. It is estimated that the COVID-19 impact on tourism is considerable, reporting about a $78 \%$ reduction in international tourism arrivals and a loss of US\$1.2 trillion in export revenues from tourism. It has also affected businesses directly connected to tourist activities and movements, with a reported 120 million job cuts (Sigala 2020).

Many of the studies addressing CT have focused on the economic or marketing perspective (Richards 2018). However, there is still a lack of data and evidence in why people engage in a particular CT form and areas and how the resources and allocated investments have a sustainable effect on the social, cultural, and environmental fields.

Furthermore, there is a knowledge gap on possible methods to measure different types of CT impacts and to assess multilevel and cross-border strategies, policies, and practices contributing to local, regional or national sustainable development. Connecting tourism and technological change opens up opportunities for preserving and sharing minority cultures and local heritage and European values beyond borders and continents.

IMPACTOUR came up with the idea to provide a framework and suggestions for these challenges by adopting a multi-value approach, considering as major impacts the social, economic, cultural and environmental dimensions.

According to what Sigala (2020) has suggested in his research, IMPACTOUR conducted a real study based on surveys, webinars, and workshops among project pilots to understand their policy makers' COVID-19 impacts and response and recovery strategies. The data is gathered mainly from data information pilots, which was challenging because of the pandemic and confinement restricting access to administrations and tourism employees and collecting data by them. To overcome these constraints, IMPACTOUR partners created gamification and joint workshops with other $\mathrm{H} 2020$ projects stakeholders, which provided an engaging and interactive environment to exchange and share experiences from all sides. 
ToSEE - Tourism in Southern and Eastern Europe, Vol. 6, pp. 587-606, 2021.

P. Pereira, J. Martins, G. Bell, T. Kalvet, S. Pasandideh: COVID-19 AND MITIGATION STRATEGIES ...

\section{LITERATURE REVIEW}

During recent decades, in many regions, tourism has become the most important and strategic industry, as it brought increasingly significant contributions to the local economy. On the other hand, tourism is also one of the most vulnerable sectors, as the COVID-19 pandemic has exposed.

In the last year, several works have been published, focused on the impact that COVID19 brought to the tourism industry and, most importantly, how tourism can and will recover from the pandemic situation. From a mathematical perspective, a study taking into account the combination of econometric and judgmental methods to forecast the tourism recovery in Hong Kong was conducted (Zhang, Song, Wen and Liu 2021). Despite the limitation of data, the authors believed that the performed analysis could provide several suggestions for business planners and policymakers regarding the tourism demand after this pandemic period. In (Fotiadis, Polyzos and Huan 2021), 12 month forecast scenarios for international tourism demand considering the COVID-19 pandemic were studied. Using neural networks, the achieved results indicate an expected reduction of between $30 \%$ and $76 \%$ in tourist arrivals, which will persist through the summer of 2021. Another work has studied and analysed data from 1995 to 2019 in 185 countries and estimated the impact of the COVID-19 outbreak on the tourism industry worldwide (Škare, Soriano and Porada-Rochon 2021). The main conclusions proposed that private and public tourism managers undertake careful assessments of the pandemic effects on business and new risk management methods developed in order to deal with the current pandemic crisis. Additionally, it is also concluded that the tourism industry recovery, at the local, regional, national or even international level, will need cooperation rather than competition to minimise costs and to provide a sense of confidence for all travellers.

From a different perspective, some authors are more focused on the communities at tourist destinations, trying to analyse the safety and well-being of locals against the costs that this population is willing to accept due to the end of tourism activities. In (Qiu, Park, $\mathrm{Li}$ and Song 2020), the social costs in three urban destinations are evaluated and compared. The findings of this study can be summarized as the following: i) recovery strategies should be formulated with a holistic and innovative mindset, ii) policies responding to COVID-19 must provide financial support not only to the tourism industry but also to other public and private sectors, in order to guarantee a balanced recovery of the destinations affected.

As far as we know, the COVID-19 pandemic is one of the most impactful diseases. As such, saving lives is the highest priority in all countries, although it is time to start the recovery process for the tourism sector, even in the limited presence of international and domestic travelers. In (Assaf and Scuderi 2020), a compilation of strategies provided by some experts in the field is presented, either from the tourism industry point of view or the role that governments should play to help the tourism sector overcoming this moment. From our point of view, the most relevant are: i) probably, tourists will gradually move from personal interactions to technologies, such as for payments or check-in kiosks, aiming to reduce the contact with others; ii) the tourism recovery will be faster as confidence in traveling increases and risk perception decreases; iii) 
ToSEE - Tourism in Southern and Eastern Europe, Vol. 6, pp. 587-606, 2021.

P. Pereira, J. Martins, G. Bell, T. Kalvet, S. Pasandideh: COVID-19 AND MITIGATION STRATEGIES ...

governments should provide funding for (re-)promoting tourism destinations, and iv) decentralised policies and strategies to be implemented in accordance with each destination situation. In (Sharma, Thomas and Paul 2021) is presented a study supported by the review of 35 papers, all published in 2020, which have analysed the tourism industry during the pandemic period. As an output of this work, authors proposed a resilient-based framework pointing out some directions for tourism recovery, grounded in four pillars: government response, technology innovation, local belongingness, and consumer and employee confidence. Authors claim that all parts involved in the tourism industry must work together, transforming it into a resilient sector characterised by sustainability, societal well-being, climate action, and the involvement of local communities which are seen as a critical aspect for the creation of opportunities for lessdeveloped tourism sites.

A study conducted in Spain that analysed the effects of the spread of COVID-19 and its impact on tourist flows and the economy is presented by (Moreno-Luna, RobinaRamírez, Sánchez and Castro-Serrano 2021). One of the main achievements is that the impact of the COVID-19 pandemic is a work in progress, and only preliminary conclusions can be drawn. Nonetheless, the authors claim that this study could be used to assist decision-makers during the pandemic recovery process. Due to the pandemic reality, the tourists' perspective could lead to them overturning their travelling preferences, avoiding overcrowded destinations, international trips, and opting for domestic and less populated places. It is expected that the domestic tourism in Spain could increase, supported by growth of rural and alternative tourism, in opposition to the mass 'sun and beach' tourism. (Rastegar, Higgins-Desbiolles and Ruhanen 2021) addresses the social, environmental and economic impacts of COVID-19, which is deepening inequalities. Therefore authors do an interesting analysis on how the pandemic has affected livelihoods from the social, economic and ecological point of view, highlighting the need to promote sustainable tourism in aiming for a fair future.

There is another side of history: the public fear caused by COVID-19 that might delay the tourism industry recovery after the pandemic ends. In (Zhang et al. 2021), a study exploring the public sense of fear, their own self-protection and resilience rules associated with travel, is presented. This study used a combination of theories, such as protection motivation theory and resilience theories, to analyse the results of a survey of 1208 respondents conducted in China. It was found that the 'public fear' has a strong correlation with the severity of the pandemic, which results in self-protective behaviour even after the pandemic ends. In order to mitigate people's 'travel fear', and boost tourism activities, a few strategies are proposed. Such strategies are mainly supported by actions that should be taken by the authorities responsible for the tourism sector. In (Rather 2021) a similar survey was made, aiming to explore the effect of fear, perceived risk and social media on tourists' behaviour and engagement during the COVID-19 crisis. As expected, it has been shown that fear of COVID-19 and perceived risk has a high negative impact on the willingness of tourists to travel. On the other hand, social media and digital platforms associated with monuments or sites positively affect tourists' engagement with such places. This positive aspect could be a key factor for tourism recovery as many responders have expressed an intention to (re)visit those places. 
ToSEE - Tourism in Southern and Eastern Europe, Vol. 6, pp. 587-606, 2021.

P. Pereira, J. Martins, G. Bell, T. Kalvet, S. Pasandideh: COVID-19 AND MITIGATION STRATEGIES ...

Since COVID-19 was declared a pandemic in the first months of 2020, it has affected all industries worldwide, where the tourism industry is, by far, the most impacted. It is expectable that tourists will somehow abstain from travel to avoid overcrowded destinations and maintain the physical distance recommend by almost all health entities. Therefore, to start the tourism industry recovery, virtual reality technology has been adopted as a way to offer tourists the opportunity to visit some monuments or sites. The work published by (ATSIZ 2021) presents a review on tourism destinations and businesses (i.e. accommodation or museums) that can use virtual reality technology to provide services, and at the same time to prevent the propagation of COVID-19. Virtual reality tools can promote and consolidate the tourism industry and gain potential new visitors in the future. Similarly, the work presented by (El-Said and Aziz 2021) analyses how stakeholders are trying to overcome the absence of tourists, and keeping their attractions in the visitors' minds by using virtual tools. To check the success of this new trend in the tourism industry, authors used Technology Acceptance Model and Protective Action Decision Model models to identify the main factors to measure the visitor's willingness to accept virtual tools as an alternative form of tourism during times of crisis. The literature review has shown that a significant number of works regarding the COVID-19 pandemic and its impact have been published. Additionally, several different approaches to analyse COVID-19 impacts from social and economic aspects to tourism industry digitalization, are offered.

\section{METHODOLOGY}

COVID-19 was an unforeseen event that had a substantial negative impact on CT pilots, and it seems that its effects will remain for a long time. While CT pilots were preparing to manage mass tourism and working on promotion plans, quarantine and closing businesses interrupted their activities for their safety. The result of the survey we disseminated among our pilots show that the main stakeholders had to deal with the following issues during the pandemic: reduction of salaries and unemployed people in the cultural tourism sector, public sector participation in financing the response to COVID-19, inhabitants visiting local attractions such as museums, changes in domestic cultural tourism visitors (domestic vs. international), SMEs under pressure. However, the lack of data and tools for monitoring and tracing the sites is reported as the most challenging and obstacle for managing the planning recovery plan.

To have more constructed and be more precise on main problems and solutions for CT pilots, in this work, we decided to make a conceptual framework based on surveys and literature reviews.

Regarding the main problem which was "Covid-19 pandemic and lack of CT tourism", and following the conceptual methodology, we answer the main question that is "During Covid-19 pandemic, what kind of issues and challenges the pilots had to be deal and how they planned for overcome them?"

The objective of the research is "To propose a best practice strategy to CT pilots to be resilient in this crisis and similar ones". 
ToSEE - Tourism in Southern and Eastern Europe, Vol. 6, pp. 587-606, 2021.

P. Pereira, J. Martins, G. Bell, T. Kalvet, S. Pasandideh: COVID-19 AND MITIGATION STRATEGIES ...

We designed an empirical research and qualitative method. The qualitative research method is defined as "the study of the nature of phenomena and is especially appropriate for answering questions of why something is (not) observed, assessing complex multicomponent interventions, and focussing on intervention improvement" (Busetto et al. 2020). The qualitative approach in this research includes several research methods such as observation, and semi-structured interviews with experts and focus group discussion and exchanging experiences. Most data are primary data that are collected from pilots but also some secondary data from universities 'research groups and tourism-related organizations. In the Figure 1, the methodology of the research is illustrated.

Figure 1: Research Methodology (inspired by Busetto et al. 2020)

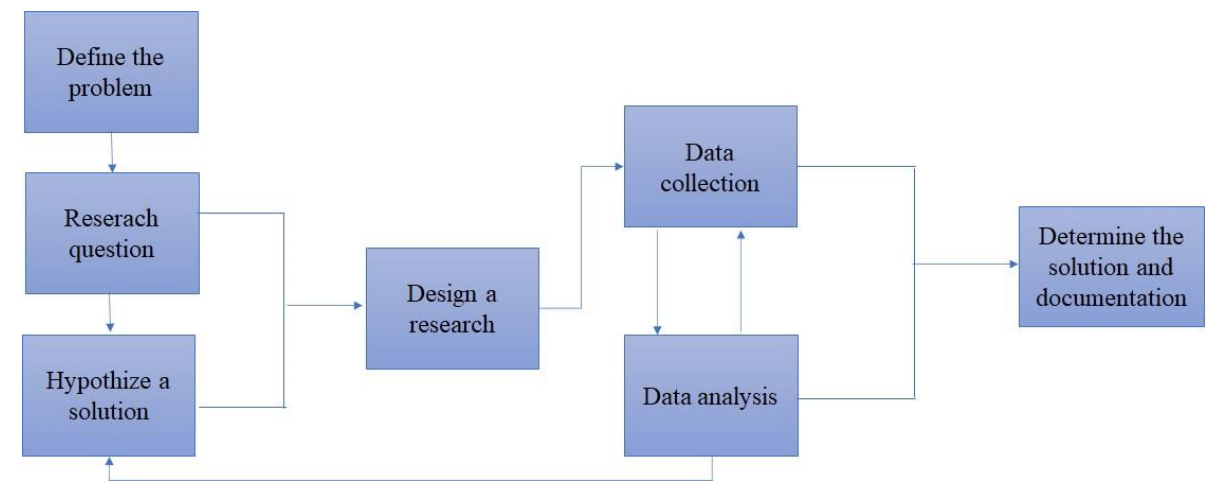

Data analysis focuses on find out what decisions are taken by tourism administers to overcome the current crisis and measuring their susses based on their tourism market data analysis. The data is harmonized and organized by experts to conduct based on the research question. In the initial observation and the outcome results from scientific papers, the type and size of organization are considered as an indicator to cluster the tourism market. Then based on interviews repots we test the hypothesis which is "The digitalization helps to most type of tourism markets and boost the tourism in crisis". At the end we propose a mitigation plan for tourism organization to be more resilient in crisis.

\subsection{Data Collection and survey structure}

Europa Nostra has undertaken a sample survey to contribute to informing IMPACTOUR at this formative stage. The scope of the survey, presented in Figure, has been restricted by COVID-19 as many organisations are closed or respondents are unable to answer because of home working. However, the survey has yielded relevant data which is probably even more informative in the current circumstances as the effects of COVID19. It has highlighted that many tourism-dependent organisations have been forced to close entirely due to not having a contingency plan (such as online digital twin sites or collections) or sufficient audience profiling and databases to target their reduced capacity most effectively. 
ToSEE - Tourism in Southern and Eastern Europe, Vol. 6, pp. 587-606, 2021.

P. Pereira, J. Martins, G. Bell, T. Kalvet, S. Pasandideh: COVID-19 AND MITIGATION STRATEGIES ...

\section{Figure 2: Cross-section of tourism market}

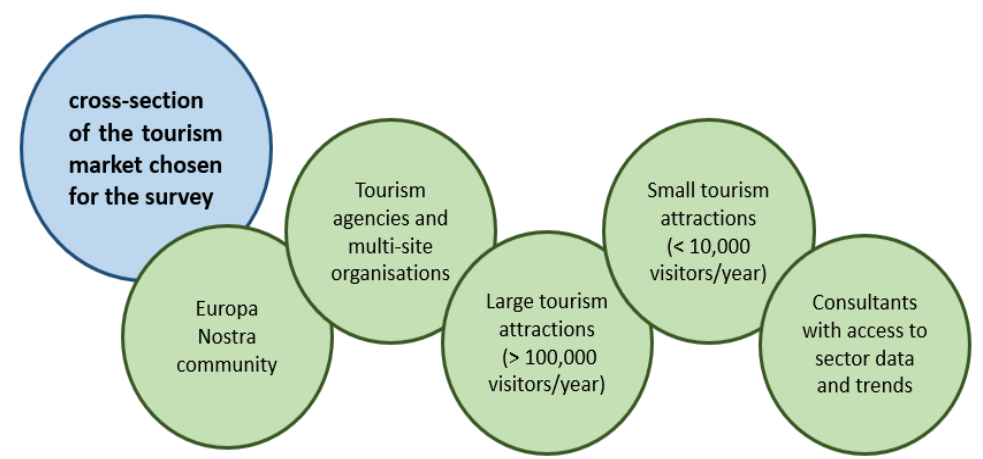

The survey was structured with the questions and respective options shown in Figure, and for IMPACTOUR, the exercise has evidenced a need, exacerbated by COVID-19, for tourism attractions and networks that are even more vulnerable or marginalised because of size (under-resourced) or lacking in expertise, especially access to performance-enhancing tools including Big/Smart Data to make them more resilient and sustainable. 'Sustainable' in this context includes flexible management and market reach, including a healthy balance where relevant and practicable between year-long community audiences and the flow of tourist visitors.

Figure 3: Survey questions

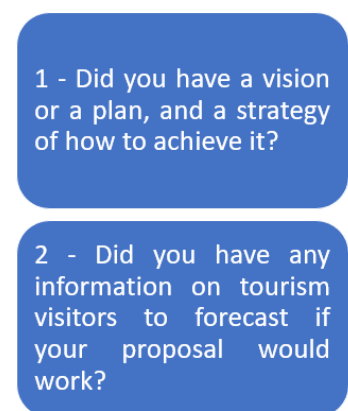

- Have you been involved in a project that restored an

ancient place or route, which tourists now use?

- Have you revived an historic festival or tradition,

which now attracts visitors?

- Have you created something which enables cultural

heritage to be experienced in new ways?

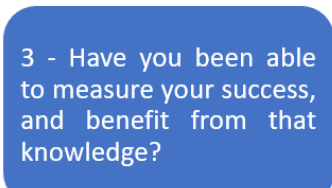

- Did you undertake surveys to find out about demand

or gauge interest in the proposal?

- Did you have access to any 'Big Data' sources as

evidence?

- Did you produce any projections or business

modelling to test the viability of the proposal?

- How have you gathered information about visitor

numbers and visitor satisfaction?

- How have you used that information to increase

visitor numbers and their quality of experience?

- If you have not had access to 'Big Data', how could it

have helped?

Most IMPACTOUR pilots rely heavily on traditional data sources in monitoring and assessing the impacts of tourism. The main sources used for the monitoring include 
ToSEE - Tourism in Southern and Eastern Europe, Vol. 6, pp. 587-606, 2021.

P. Pereira, J. Martins, G. Bell, T. Kalvet, S. Pasandideh: COVID-19 AND MITIGATION STRATEGIES ...

official (national-level) tourism statistics, which are most often based on visitor surveys and do not distinguish CT from other types of tourism. Visitor statistics are also collected directly from accommodation facilities, tourism site operators and event organisers. Some pilots, such as Aldeia dos Biscoitos in the Azores, conduct visitor surveys at specific visitation points.

\subsection{Survey Analysis and outcome Results}

The pilots use the secondary data which are receive from other data providers and not providing themselves such as numbers of museum's visitors are provided by the relevant ministries or analysing mobile data, also from transportation hubs. The municipalities consider these datasets are a key source for monitoring tourism flows.

The Tourist Information System (TIS) consolidates information supplied by tourist sites on accommodation, heritage, leisure, activities, centres, events, etc., and gives a comprehensive picture of tourism supply in the region.

The responses of this survey, from different types of organisations or attractions, enabled some pertinent conclusions related to digitalisation and data for $\mathrm{CT}$, summarized in Figure .

Figure 4: Responses survey highlights
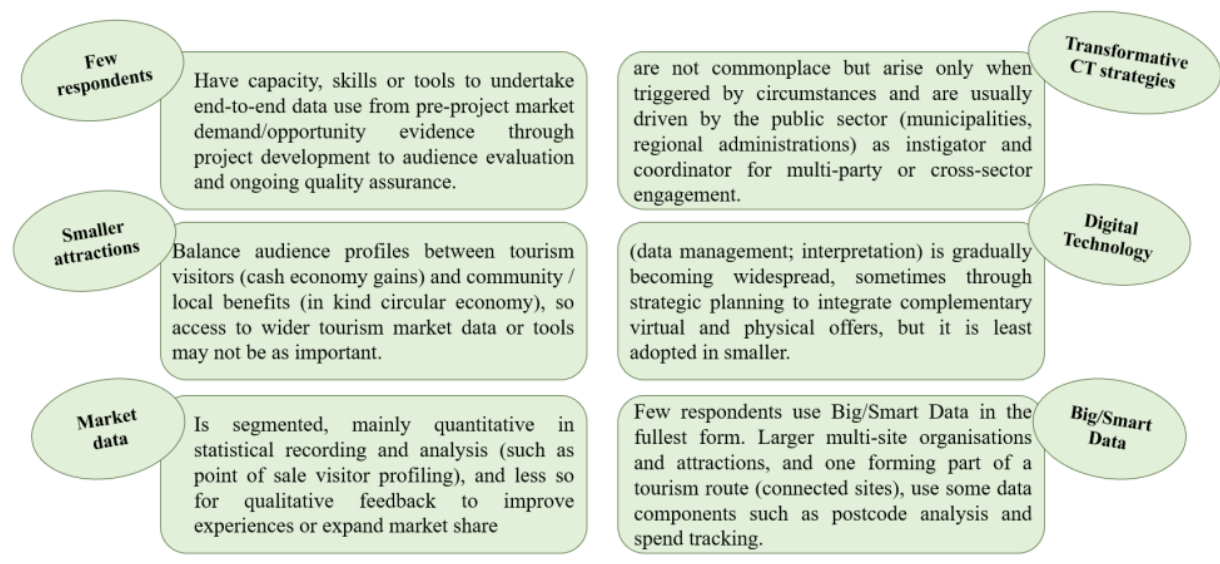

\subsection{COVID-19 IMPACT on PILOTS}

Moreover, some pertinent conclusions connected with the tourism market during the COVID-19 pandemic were made possible by tracking some organisations, attractions, or tourism agencies. These conclusions are presented in Figure . 
ToSEE - Tourism in Southern and Eastern Europe, Vol. 6, pp. 587-606, 2021.

Figure 5: Tourism market tracking during Covid-19
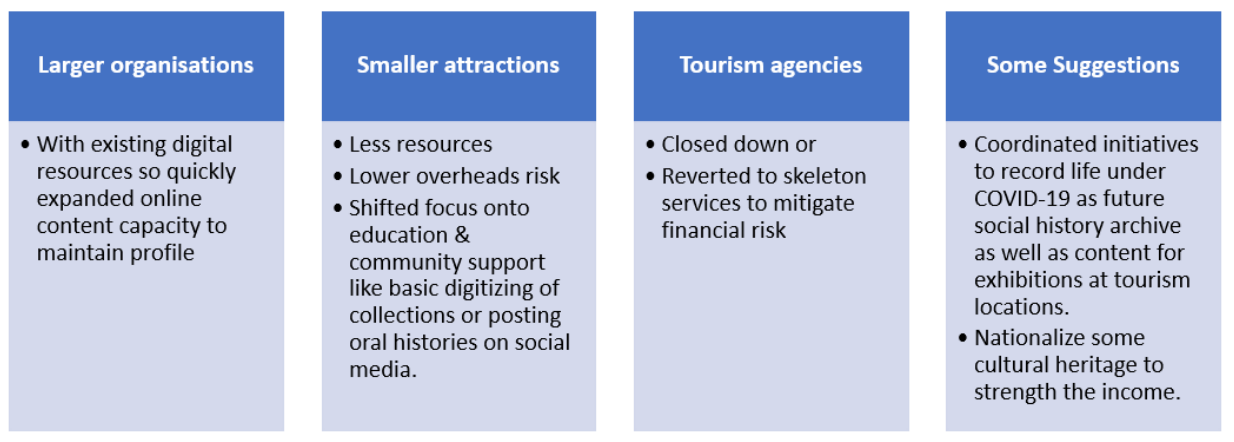

\section{MITIGATION STRATEGIES}

According to the outcome results of the survey, webinars, internal workshops, one of the primary and essential mitigation plans should be to implement resilient strategies in the tourism sector. Resiliency in tourism management plans will have a paramount impact on assessment, promotion, recovery, and keeping tourism alive in any threatening situation, such as a pandemic.

\subsection{Resilient Cultural Tourism}

The main recommendation that COVID-19 and related crises have provided for CT development is the need of resilient CT strategies. Tourism is invariably subject to buffeting from change that often occurs outside and beyond its control and from within, necessitating the development of adaptive capacities, internal and external, slow and fast, drivers of change (Cheer and Lew 2021). COVID-19 led to a fast (and dramatic) change for the economy worldwide which has directly affected the CT sector, and, above all, the community.

In Figure, spatial scales at which resilience operates in a tourism context are defined. These two scales distinguish between community resilience and business resilience, an important distinction given that the drivers of tourism change and development can have very different aims (European Commision 2020). Being prepared to change (slow or fast driven) means the community (public, private and citizens) being resilient to disasters or external emergencies, and this can only be reached by collaborative planning (Filimonau and De Coteau 2020).

It is being demonstrated that COVID-19 has represented an overwhelming threat to CT. However, it could also be a unique opportunity for boosting a new paradigm. Sustainable CT has lately been the focus of governments and the tourism sector or tourism managers, but what has arisen as one of the consequences of the COVID-19 pandemic is the need for resilient CT, more than a focus on sustainable tourism: "While sustainability is a 
ToSEE - Tourism in Southern and Eastern Europe, Vol. 6, pp. 587-606, 2021.

P. Pereira, J. Martins, G. Bell, T. Kalvet, S. Pasandideh: COVID-19 AND MITIGATION STRATEGIES ...

more holistic and linear approach concerned, in the main, with preserving finite resources, resilience incorporates more systemic thinking around preparedness to avoid disaster and the ability to re-bounce after the crisis" (Filimonau and De Coteau 2020).

Figure 6: Scale, change and resilience in tourism (Cheer and Lew 2021)

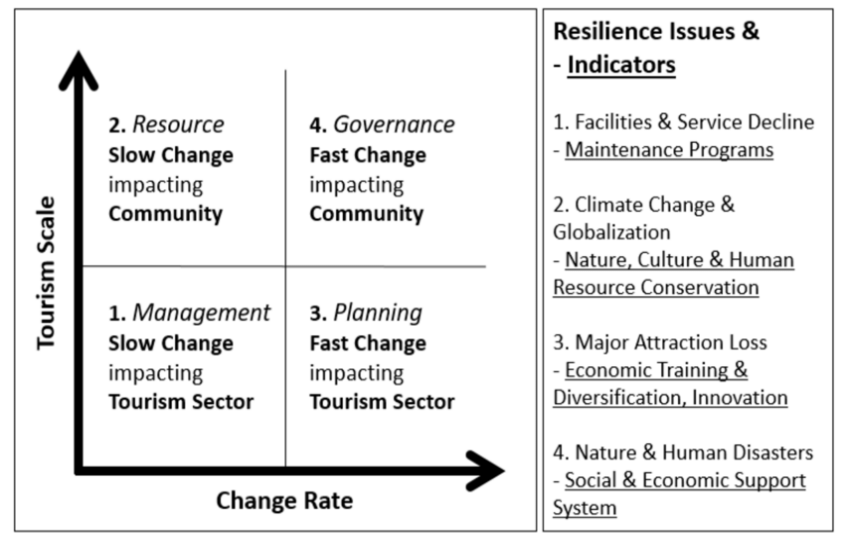

Thus, we can use COVID-19 to understand the resilience of CT strategies. European institutions are key organisations in this, and there are ongoing discussions on how the European Commission should answer to the effects that the coronavirus crisis has had on significant initiatives, such as the European Capital of Culture. Extension of the 2020 Capitals of Culture (Rijeka in Croatia and Galway in Ireland) are being planned, and forthcoming years' Capitals of Culture may also be postponed, proving proving the European Commission's capacity institutions to be adaptive to such crises.

\subsection{Local Communities Empowerment}

Travels have been traditionally separated into two categories: International Tourism, which crosses the boundaries of countries, versus Domestic Tourism, defined as the act of travelling within one's home country. The edges between one and the other overlap there are sites with (and focused on) international tourism that have plenty of domestic tourism, and vice-versa - but one conclusion that we can obtain from the current social and economic crisis is that these trends have also shifted. The summer of 2020 provided a clear example of international CT changing into domestic CT. A typical cultural tourist has changed from choosing an international destination into a domestic one. Nevertheless, there is also a change in the definition of domestic tourism, which is especially related to the way of travelling, which shifted from air to terrestrial transport. This leads to a revision of the term "boundary", which is not strictly related to areas within a country, but to a distance that can be easily reached within the home country or a nearby country. Many governments in Europe quickly developed strategies for boosting demand on domestic tourism (OCDE 2020). Moreover, in this same way, innovation and local tourism is being more and more identified as key to re-design Europe's cultural and creative cities (Montalto, Sacco, Alberti, Panella and Saisana 
ToSEE - Tourism in Southern and Eastern Europe, Vol. 6, pp. 587-606, 2021.

P. Pereira, J. Martins, G. Bell, T. Kalvet, S. Pasandideh: COVID-19 AND MITIGATION STRATEGIES ...

2020). Some of the first research studies on the impacts of COVID-19 have underlined that, if well managed, touristic countries could have a considerable portion of international visitors substituted by domestic tourists, which will allow them to adapt to crises more easily (Helble and Fink 2020). Countries are already betting on this; for instance, Italy is ,promoting "proximity" tourism by financing six relevant creative projects during the following months (Maida 2020).

All tourism stakeholders can take action to increase local engagement and ownership. For instance, tourism accommodation and hotels can provide a market for locally produced foods, for local linens, furniture, and artwork. Tourists can supply an important market for local crafts and souvenirs, drawing upon local traditions and skills. They can also provide the audience with music, songs and stories. Tour routes, interpretation centres and attractions can provide opportunities for local guides who can supply unrivalled knowledge and insights into local customs and traditions. Moreover, such services and goods can be delivered at highly competitive but fair prices based upon their immediacy.

The Barcelona Declaration, "Better places to live, better places to visit" highlights that "What is good for residents is good for visitors". The residents and the local community should be the main beneficiaries of any activity developed in the place they live. They must be consulted and included in the decision-making process from its early stage. Community empowerment and community participation are key factors in avoiding conflicts between the shared uses of cultural heritage sites/places and between residents and visitors.

The decentralisation of tourism and local governments' role in designing and implementing cultural and tourism policies are key to promoting sustainable growth, creating jobs, and promoting local culture and products, in line with SDG 8 (Baltà 2019). This can be achieved by the strengthening of local cultural policies and participatory governance frameworks.

\subsection{Importance of Cultural Tourism Impact Assessment on Increase}

Despite the IMPACTOUR pilots' fascination with integration of sort of new tools into existing data management, it has challenges and barriers in case of using nonconventional data sources. The privacy regulation is the commonly cited issue (especially limiting the use of Mobile Positioning Data), or owner of relative data are private parties and accessibility needs to be charged by customer of data. Also, it is seen that smaller tourism destinations generally have limited awareness regarding new tools and their application. Several pilots, particularly in smaller localities, have mentioned of limited data analysis capabilities, which mostly is referred to financial and human resource constraints. Besides the inaccessibly to information and relative data, possible biases in data analysis are expressed by some pilots that is because of lack of data quality. Moreover, it is another problem regarding comparability and compatibility of data aggregated from different sources. These issues have highlighted the importance of standardisation and interoperability of techniques and tools are used in across regions and country borders. 
ToSEE - Tourism in Southern and Eastern Europe, Vol. 6, pp. 587-606, 2021.

P. Pereira, J. Martins, G. Bell, T. Kalvet, S. Pasandideh: COVID-19 AND MITIGATION STRATEGIES ...

Experience with the IMPACTOUR pilots shows that COVID-19 crisis makes monitoring the impact of tourism strategies even more important now and this, thereafter, makes real-time or close to real-time data collection and treatment more necessary than ever. Digital technologies and data have a valuable role to play in combating the pandemic. In line with data protection law, mobile applications, Artificial Intelligence (AI) and robotics can help monitor physical distancing or even facilitate disinfection, especially in places with regular tourism flows. The development of rapidly updated analytical dashboards may be an attractive alternative for updated and real-time results. COVID19 has triggered an extraordinary rapid adoption of digital tools to ensure tangible and intangible preservation of heritage sites and their visibility during and after the lockdown, also relating to management and governance enhanced by novel tools.

\subsection{Innovative tools for management and governance}

Currently, significant changes are taking place regarding policy monitoring and evaluation as well as data and tools usages. Specifically, these changes include: (1) The importance of evidence has increased considerably in policy planning, implementation, and evaluation, (2) there is an unprecedented availability of open and big data, and (3) there are rapid developments in intelligence gathering and the application of analytical tools (OPSI 2019). Such trends are also taking place in the terms of tourism, and the roles of data science, and smart and big data analytics, are becoming increasingly important (Kalvet, Olesk, Tiits and Raun 2020). It is expected that in the long run traditional surveys will replaced with other data sources which dramatically are increasing (Demunter 2017). New data fusion and analysis tools and techniques supports processing the immense volume of information to achieve the near real-time synchronisation of sources and carry out analyses on a more detailed level (Guilarte and Quintáns 2019, Volo 2018, Xu et al. 2020). Along those, predictive analytics is getting more attentions.

Overall, it seems emerging tools for CT impact assessment be positioned in four key domains: (1) Mobile Positioning Data, (2) World Wide Web Data, (3) Data on Sharing and Collaborative Economy, and (4) Passenger Data (Kalvet et al. 2020; Pérez Guilarte and Barreiro Quintáns 2019). However, the developments are accompanied by challenges related to the data issues such as access, complexity, objectivity, quality, and competencies, also coordination between different stakeholders, and competencies. In this regard, access to proprietary data particularly and access regulation for public purposes-for example for anonymised data- is likely to remain a matter of controversy in the future (Demunter 2017).

The increasing reliance of tourism on Information and Communication Technologies (ICT) and data has been captured in the concept of 'smart tourism', which could be defined as "tourism supported by integrated efforts at a destination to collect and aggregate/harness data derived from physical infrastructure, social connections, government/organizational sources and human bodies/minds in combination with the use of advanced technologies to transform that data into on-site experiences and business value-propositions with a clear focus on efficiency, sustainability and experience enrichment" (Gretzel, Sigala, Xiang and Koo 2015). The key component of smart tourism is smart destinations integration of tradition tourism infrastructure and ICT 
ToSEE - Tourism in Southern and Eastern Europe, Vol. 6, pp. 587-606, 2021.

P. Pereira, J. Martins, G. Bell, T. Kalvet, S. Pasandideh: COVID-19 AND MITIGATION STRATEGIES ...

which brough the definition of Internet of Things (IoT). IoT sensors to measure and manage the movement of people; providing tourists with location-based information via smartphone apps, collecting real-time public transportation location information and sharing this life on information displays in bus stops, and so on (Gretzel et al. 2015). The smart tourism mainly enhances and support traveller's relatively experiences and needs, however, the generated data of tourism activities helps. In this regard, tourist's role in the smart tourism framework is co-creators of valuable data through creating and uploading hashtags photos, videos taken from their destinations on social media platforms, or data obtained via crowd mapping points of interests (POIs), and wearable and mobile sensors.

Travel and tourism have been hit particularly hard by the COVID-19 crisis, and feedback from CT experts and the participating regions indicated that these previously identified trends are receiving additional attention due to recent developments. Therefore, the government and tourism managers need urgent information about CT departments and tourism companies to develop policy tools; and in Europe it is possible to learn from each other on the most effective instruments. These aspects make the adoption of smart and big data in CT management even more appealing than it might have been otherwise.

\section{SUSTAINABILITY-GREEN-DIGITAL TRIANGLE: THE IMPACTOUR MITIGATION PLAN}

During the crisis such as the current pandemic local committees plays a pivotal role to plan mitigation strategies and execute them. Local committees should learn how to cultivate resilience, discover new ways of Cultural Tourism promotion, and better communicate their local cultural and natural splendours. Each place is unique, and that should be advertised as a major attraction. New ways of enlightening local communities should be pursued. Local communities, the ones more affected by the Cultural Tourism drawback, must be prepared and pave the way by contributing to economic recovery.

Support efforts for the recovery of tourism, the UNWTO has begun a series of publications entitled, "Inclusive Recovery Guide - Sociocultural Impacts of COVID19”. Issue 1 (December 2020) concerns Persons with Disabilities (UNWTO 2020), while Issue 2 (February 2021), developed in collaboration with UNESCO, addresses "Harnessing the Power of Culture and Creativity in Tourism" (UNWTO 2021).

The platform 'Tourism for Sustainable Development Goals ', developed by the UNWTO World Tourism Organization, identifies 17 goals to guide advancement towards sustainable tourism in line with the 2030 Agenda (UNWTO 2019). In all the goals, the keyword to move forward is local empowerment. Encouraging " $a$ participatory approach to the governance of cultural heritage places with local/community involvement through multi-stakeholder participation structures" is a critical factor for achieving sustainability.

In 2019, the OMC (Open Method of Coordination) working group of the EU came up with a report with recommendations on how to best approach the topic ("Sustainable 
ToSEE - Tourism in Southern and Eastern Europe, Vol. 6, pp. 587-606, 2021.

P. Pereira, J. Martins, G. Bell, T. Kalvet, S. Pasandideh: COVID-19 AND MITIGATION STRATEGIES ...

cultural tourism - Publications Office of the EU" 2019). Their 55 recommendations can be grouped into four main domains:

- First, the "need to urgently establish a European Over-Tourism Task Force comprising the main stakeholders who monitor cultural heritage destinations at risk or in a state of over-capacity and report annually on trends".

- Second, the need to "break down silos that exist between stakeholders by mainstreaming, collaborating and creating synergies at the various levels".

- Third, the need to "promote community ownership", through training and awarenessraising and by discouraging seasonality and promoting lesser-known sites and cultural heritage practices. The latter can be achieved by providing incentives for and encouraging local participation in networking, partnering schemes, synergies, collaborations, programmes, and initiatives, among others.

- Fourth, to develop digital tools and technology to facilitate remote access. Increasing community ownership also resonates with UNESCO's priorities (see, e.g., Robinson and Picard 2006).

On May 13 2020, the European Commission published its guide on "how to safely resume travel and reboot Europe's tourism in 2020 and beyond" (European Commision, 2020). As the lockdown triggered by the COVID-19 virus was assumed to be easing, and the ban on travel would soon be lifted, this guide explored how to make travelling and tourism safe. However, time showed that this easing was short-lived and, entering 2021, the prospect of when and how to "restart" tourism in Europe and globally is under continual discussion, with the availability and efficacy of vaccinations becoming a key factor in the debate.

While it is true that traveling might see an increase in the numbers of COVID-19 cases, reopening the borders begs another question: How do we ensure that tourism becomes more sustainable? Indeed, with the hard reset that the virus has forced on the sector, now is a perfect time to reconsider how tourism is being practiced and move on to more innovative, sustainable ways.

Rethinking a 'sustainable, digital and resilient European tourism sector' resonates with what European Commissioner for Internal Market, Thierry Breton, already expressed in an address to the European Parliament on April 21, 2020 (Breton 2020). IMPACTOUR aims to contribute to this objective, translating these vital policy objectives into concrete actions to use sustainable $\mathrm{CT}$ as a vector for local development and to rebuild local economies that have suffered from the impact of the health crisis. Thus, providing tourism and cultural heritage managers with guidelines and recommendations for innovative and transformative strategies on their CT management is becoming more essential than ever. Re-balancing means diversification of CT activities, diversification of tourist types and diversification of marketing regarding incoming tourists' origins (national and international). In the end, the more diverse CT is, the more diverse the socioeconomic activity is - thus, the more resilient a site is to emergencies of all types (including COVID-19 but also any other). 
ToSEE - Tourism in Southern and Eastern Europe, Vol. 6, pp. 587-606, 2021.

P. Pereira, J. Martins, G. Bell, T. Kalvet, S. Pasandideh: COVID-19 AND MITIGATION STRATEGIES ...

Due to COVID-19, 'over tourism' has changed to 'no tourism' and the necessity to adapt and overcome the consequences, as presented in Figure 7, leads us to (re)discover how tourism might be reinvented.

Figure 7: Consequences of Covid-19 on tourism

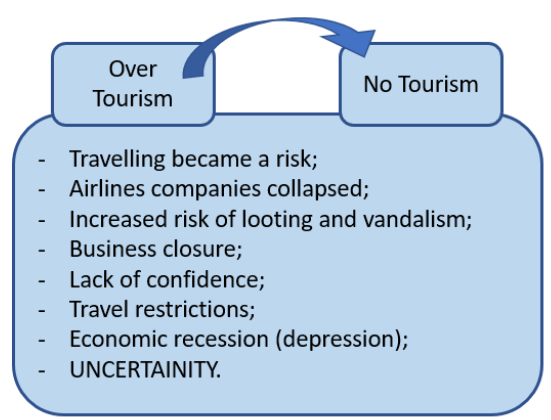

The relationship between sustainable, green and digital tourism, presented in Figure, is a new paradigm for tourism recovery after a pandemic crisis that affected in a large scale the way CT is seen and thought about. The IMPACTOUR Sustainability-Green-Digital (SGD) Triangle represents and connects the key areas that are foreseen as driving forces for CT recovery.

\section{Figure 8: IMPACTOUR SGD triangle}

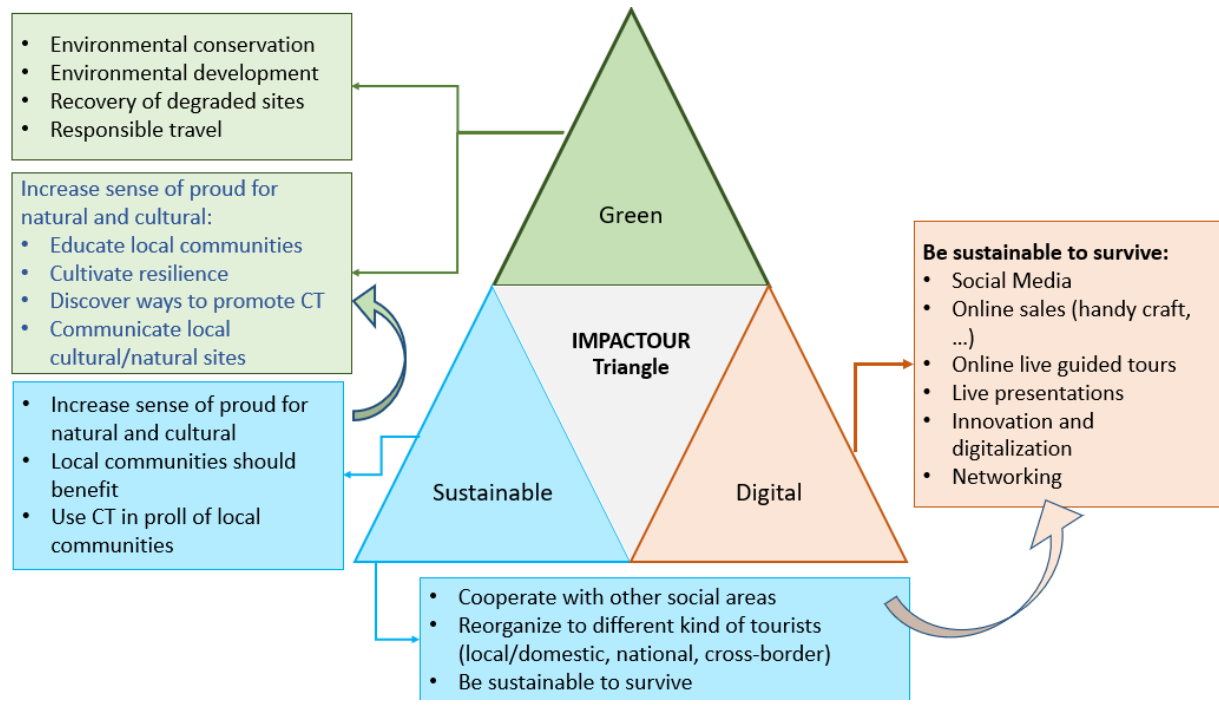

In the IMPACTOUR SGD Triange, sustainability is connected with people and local communities, and how distinct stakeholders and sites can cooperate amongst themselves, promoting diversity and self-reorganising to better adapt to different kinds of tourists. This approach must gather all generations (young, adult and senior people), sharing 
ToSEE - Tourism in Southern and Eastern Europe, Vol. 6, pp. 587-606, 2021.

P. Pereira, J. Martins, G. Bell, T. Kalvet, S. Pasandideh: COVID-19 AND MITIGATION STRATEGIES ...

knowledge and experience, increasing the sense of community and creating a strong commitment with the place where they live.

A green CT means that tourist places must be preserved and developed taking into account their environment. Thus, it is fundamental to keep natural resources wellmaintained, to develop the ones less known and to recover those sites that are degraded by many reasons. This can be achieved by making some investments and bringing local communities into the decision process, educating them and stressing the value they can bring to the local economy. If local communities can benefit from this process, the sense of pride for their natural and cultural history will rise, and at the same time will increase their engagement, making them the most valuable ambassadors of their sites.

Digital tools supporting the new era of tourism are needed. During the COVID-19 pandemic, people have become more engaged with technology. Providing attractive activities and promoting local sites through online platforms will engage tourists in advance amongst many other opportunities. Those are for sure tourists that will go there and visit in person. Additionally, data collection is also needed. Data analysis can play an important role in business models, as it might allow profiling tourists aiming to create new CT activities. Moreover, big data and data analysis are also fundamental instruments for tourism stakeholders who can benefit from technological decision-making platforms capable of transforming information into knowledge.

The combination of these three factors, sustainability, green and digital, is crucial for the new CT era after the present pandemic crisis.

\section{OPEN ISSUES AND FUTURE WORKS}

It is common knowledge that the tourism sector, which accounted for $9 \%$ of the worldwide GDP and $8 \%$ of total employment in 2019 , and particularly the Cultural Tourism sector, which represented $37 \%$ of the tourism sector with a $15 \%$ annual growth in 2018 , were deeply impacted by the current pandemic. We can say these were the short-term solutions, but much more needs to be done. The sustainability of CT is now undoubtedly connected with local communities, which can be an active part in the CT recovery process and strategy, increasing their sense of pride, whether that lies in the cultural or natural environment. Citizens can be great representatives of their local cultural and natural history.

One of future work in making cultural tourism more resilient is to rethink and rebuild global tourism.

Overall, the COVID-19 crisis has offered an opportunity to rethink and rebuild global tourism in a more sustainable way. This includes CT as probably one of the most sustainable forms of tourism and means reimagining and rebuilding destinations, encouraging businesses to build resilience.

Rethinking and rebuilding global tourism consists of more efforts for bringing stakeholders together, collecting data from travel industry players to track the impact of tourism activity, adjusting KPIs so that tourism success is measured by 'high-value low impact', and assisting SMEs in their business recovery (Day 2020). Most of these 
ToSEE - Tourism in Southern and Eastern Europe, Vol. 6, pp. 587-606, 2021.

P. Pereira, J. Martins, G. Bell, T. Kalvet, S. Pasandideh: COVID-19 AND MITIGATION STRATEGIES ...

measures may not be new, but COVID-19 has made them more needed than ever. Indeed, this rethinking has already started all around Europe, especially in locations that have enjoyed (or suffered) mass tourism in the last decades or years (Wissgott 2020).

At the level of individual tourism businesses, operators are working to apply social distancing and other health measures to remain in operation, albeit at a lower level. For those who depend on local and domestic tourism, this is particularly important.

\section{CONCLUSION}

The research conducted was focused on the COVID-19 pandemic impact on Cultural Tourism. It has highlighted the need for rethinking how tourism is approached. The presented results are achieved based on data gathered from surveys, webinars, and workshops, which were organised in the framework of the IMPACTOUR project or carried out by its partners.

It is undeniable that the current pandemic situation has a substantial negative impact on $\mathrm{CT}$, and its effects will remain for a long time. The business closure, travel restrictions, and economic recession are clear evidence of the pandemic effect. On the other hand, right after the pandemic started, many CT stakeholders found in digital a way to overcome the absence of tourists and remain close to those willing to visit certain monuments or sites virtually. Nevertheless, the obtained results showed that the pandemic could be seen as an opportunity to apply new technologies and test our solidarity, cooperation, and resilience as a society.

A dynamic tourism economy depends on the availability of various services within destinations, from accommodation and food to attractions, activities, and events (OCDE 2020). The end of the COVID-19 crisis is unpredictable, but if tourism were not diverse enough, the economic activity would not have been sustainable in the long term, as it could not be resilient to changes.

One of the essential mitigation plans to overcome the crisis on cultural tourism is rethinking existing business models and providing resilient strategies for the tourism industry. Our studies showed that engaging and empowering local committees, applying the innovative tools for managing and standardisation and interoperability of systems and tools across regions and country borders are some strategies that help stakeholders operate more efficiently in different situations.

This paper proposed a sustainability-green-digital-triangle as a new resilient approach to boost the CT sector, which tries to interconnect the key factors that we foresee as driving forces for CT recovery. This approach puts together citizens, stakeholders, decision, and policymakers, collaborating to promote CT diversity, aiming to attract different kinds of tourists.

Resilient and sustainable cultural tourism can be achieved by: i) creating strong community engagement, ii) preserving and developing cultural and natural patrimony, and iii) using digital tools, based on data analysis, as a way to create knowledge and also to as a way to engage the digital tourist. 
ToSEE - Tourism in Southern and Eastern Europe, Vol. 6, pp. 587-606, 2021.

P. Pereira, J. Martins, G. Bell, T. Kalvet, S. Pasandideh: COVID-19 AND MITIGATION STRATEGIES ...

\section{ACKNOWLEDGEMENTS $\llbracket$}

This work has been supported in part by the project IMPACTOUR, "IMproving Sustainable Development Policies and Practices to access, diversify and foster Cultural TOURism in European regions and areas" which has received funding from the European Union's Horizon 2020 research and innovation programme under grant agreement No 870747.

The authors acknowledge Adriana Mar, for her contribution for the graphics and images on this work.

\section{REFERENCES}

Assaf, A. and Scuderi, R. (2020), "COVID-19 and the recovery of the tourism industry", Tourism Economics, Vol. 26, No. 5, pp. 731-733. https://doi.org/10.1177/1354816620933712

ATSIZ, O. (2021), "Virtual reality technology and physical distancing: A review on limiting human interaction in tourism", Journal of Multidisciplinary Academic Tourism, Vol. 6, No. 1, pp. 27-35. https://doi.org/10.31822/jomat.834448

Baltà, J. (2019), UCLG Committee. Local Culture and Tourism, SDG 8.9. Devise and Implement Policies to Promote Sustainable Tourism that Creates Jobs and Promotes Local Culture and Products, viewed 19 May 2021, http://www.agenda21culture.net/sites/default/files/hlpf12019_-_8.9.pdf

Breton, T. (2020), European Parliamnent Committee on Transport and Tourism, Speech by Commissioner Breton on "A Marshall Plan for European Tourism", viewed 20 May 2021, https://ec.europa.eu/commission/commissioners/2019-2024/breton/announcements/speechcommissioner-breton-marshall-plan-european-tourism en

Cheer, J. and Lew, A.A. (2021), "Understanding tourism resilience: Adapting to social, political and economic change", Tourism, Resilience and Sustainability, Routledge, pp. 7-13. https://doi.org/10.4324/9781315464053-1

Day, J. (2020), Sustainability Leaders Project, Tourism Recovery vs. Destination Sustainability Post-COVID viewed 19 May 2021, https://sustainability-leaders.com/tourism-recovery-vs-destinationsustainability-post-covid

Demunter, C. (2017), Eurostat, Tourism Statistics: Early Adopters of Big Data, Luxemburg: Publications Office of the European Union. https://ec.europa.eu/eurostat/documents/3888793/8234206/KS-TC17-004-EN-N.pdf

El-Said, O. and Aziz, H. (2021), "Virtual Tours a Means to an End: An Analysis of Virtual Tours' Role in Tourism Recovery Post COVID-19", Journal of Travel Research. https://doi.org/10.1177/0047287521997567

European Commision (2020), "Tourism and transport: Commission's guidance on how to safely resume trave and reboot Europe's tourism in 2020 and beyond", viewed 18 May 2021, https://ec.europa.eu/commission/presscorner/detail/en/ip_20_854?utm_campaign=59b7d20894a3 26107700117f\&utm_content=5ebbf28410a36c0001776e58\&utm_medium=smarpshare\&utm_sou rce $=$ generic

Filimonau, V. and De Coteau, D. (2020), " Tourism resilience in the context of integrated destination and disaster management (DM 2 )", International Journal of Tourism Research, Vol. 22, No. 2, pp 202-222. https://doi.org/10.1002/jtr.2329

Fotiadis, A., Polyzos, S. and Huan, T.-C.T. (2021), "The good, the bad and the ugly on COVID-19 tourism recovery", Annals of Tourism Research, Vol. 87, No. 2. https://doi.org/10.1016/j.annals.2020.103117

Gretzel, U., Sigala, M., Xiang, Z. and Koo, C. (2015), "Smart tourism: foundations and developments", Electronic Markets, Vol. 25, No. 3, pp. 179-188 https://doi.org/10.1007/s12525-015-0196-8

Helble, M. and Fink, A. (2020), "Reviving Tourism amid the COVID-19 Pandemic", ADB Briefs, Vol. 1, No. 150, pp. 1-13 http://dx.doi.org/10.22617/BRF200245-2

Kalvet, T., Olesk, M., Tiits, M. and Raun, J. (2020), "Innovative Tools for Tourism and Cultural Tourism Impact Assessment. Sustainability", Vol. 12, No. 18, 7470. https://doi.org/10.3390/su12187470

Maida, D. (2020)," "Viaggio in Italia", il bando lanciato dal MiBACT per promuovere il turismo di prossimità", viewed 19 May 2021, https://www.artribune.com/jobs/2020/09/viaggio-in-italia-il-bando-lanciatodal-mibact-per-promuovere-il-turismo-di-prossimita/

Montalto, V., Sacco, P.L., Alberti, V., Panella, F. and Saisana, M. (2020), "European Cultural and Creative Cities in COVID-19 times", Publications Office of the European Union: Luxembourg, 
ToSEE - Tourism in Southern and Eastern Europe, Vol. 6, pp. 587-606, 2021.

P. Pereira, J. Martins, G. Bell, T. Kalvet, S. Pasandideh: COVID-19 AND MITIGATION STRATEGIES ...

https://publications.jrc.ec.europa.eu/repository/handle/JRC120876

Moreno-Luna, L., Robina-Ramírez, R., Sánchez, M.S.-O. and Castro-Serrano, J. (2021), "Tourism and Sustainability in Times of COVID-19: The Case of Spain", International Journal of Environmental Research and Public Health, Vol. 18, No. 4, 1859. https://doi.org/10.3390/ijerph18041859

OCDE (2020), "OECD Tourism Policy Responses to the coronavirus (COVID-19)", OECD, https://doi.org/10.1787/6b47b985-en

OPSI (2019), "Embracing innovation in Goverment: Global trends 2019", World Government Summit, viewed https://www.oecd.org/innovation/innovative-government/embracing-innovation-in-governmentglobal-trends-2019.htm

Pérez Guilarte, Y. and Barreiro Quintáns, D. (2019), "Using Big Data to Measure Tourist Sustainability: Myth or Reality?", Sustainability, Vol. 11, No. 20. https://doi.org/10.3390/su11205641

Qiu, R.T.R., Park, J., Li, S. and Song, H. (2020), "Social costs of tourism during the COVID-19 pandemic" Annals of Tourism Research, Vol. 84, 102994. https://doi.org/10.1016/j.annals.2020.102994

Rastegar, R., Higgins-Desbiolles, F. and Ruhanen, L. (2021), "COVID-19 and a justice framework to guide tourism recovery", Annals of Tourism Research, 6 Feb 2021, 103161 https://doi.org/10.1016/j.annals.2021.103161

Rather, R.A. (2021), "Monitoring the impacts of tourism-based social media, risk perception and fear on tourist's attitude and revisiting behaviour in the wake of COVID-19 pandemic", Current Issues in Tourism, pp. 1-9 https://doi.org/10.1080/13683500.2021.1884666

Robinson, M. and Picard, D. (2006), "Tourism, culture and sustainable development"; UNESDOC Digital Library. Retrieved from https://unesdoc.unesco.org/ark:/48223/pf0000147578

Sharma, G.D., Thomas, A. and Paul, J. (2021), "Reviving tourism industry post-COVID-19: A resilience-based framework", Tourism Management Perspectives, Vol. 37, No. 4, 100786. https://doi.org/10.1016/j.tmp.2020.100786

Škare, M., Soriano, D.R. and Porada-Rochoń, M. (2021), "Impact of COVID-19 on the travel and tourism industry", Technological Forecasting and Social Change, Vol.163, 120469. https://doi.org/10.1016/j.techfore.2020.120469

European Agenda for Culture (2019), Sustainable cultural tourism, viewed 18 May 2021, https://op.europa.eu/en/publication-detail/-/publication/1aeff746-2255-11ea-af8101aa75ed71a1/language-en

UNWTO (2017), Definitions committee on tourism and competitiveness, CTC, http://cf.cdn.unwto.org/sites/all/files/docpdf/ctcdefinitionsenweb.pdf

UNWTO (2019), Tourism for SDGs - Welcome To The Tourism For SDGs Platform!, viewed 19 May 2021, https://tourism4sdgs.org/

UNWTO (2020), UNWTO Inclusive Recovery Guide - Sociocultural Impacts of Covid-19, Issue I: Persons with Disabilities, https://doi.org/10.18111/9789284422296

UNWTO (2021), UNWTO Inclusive Recovery Guide - Sociocultural Impacts of Covid-19, Issue 2: Cultural Tourism, https://doi.org/10.18111/9789284422579

Wissgott, S.S. (2020), "Rethinking Venice tourism post-COVID-19", CGTN, https://news.cgtn.com/news/2020 09-10/Rethinking-Venice-tourism-post-COVID-19-TFKy60Q4s8/index.html

Zhang, H., Song, H., Wen, L. and Liu, C. (2021), "Forecasting tourism recovery amid COVID-19", Annals of Tourism Research, Vol. 87, 103149. https://doi.org/10.1016/j.annals.2021.103149 
ToSEE - Tourism in Southern and Eastern Europe, Vol. 6, pp. 587-606, 2021.

P. Pereira, J. Martins, G. Bell, T. Kalvet, S. Pasandideh: COVID-19 AND MITIGATION STRATEGIES ...

Pedro Pereira, PhD, Assistant Professor

CTS-UNINOVA

NOVA School of Science and Technology | FCT NOVA

Department of Electrical and Computer Engineering Campus FCT NOVA, 2829-516, Caparica, Portugal pmrp@fct.unl.pt

João Martins, PhD, Associate Professor with Habilitation CTS-UNINOVA

NOVA School of Science and Technology | FCT NOVA

Department of Electrical and Computer Engineering Campus FCT NOVA, 2829-516, Caparica, Portugal

jf.martins@fct.unl.pt

Graham Bell, Board Member

Europa Nostra

Lange Voorhout 35,

NL - 2514 EC The Hague

Graham.Bell@culturatrust.org

Tarmo Kalvet, $\mathrm{PhD}$, Research Director

Institute of Baltic Studies

Lai 30, 51005, Tartu, Estonia

tarmo@ibs.ee

Shabnam Pasandideh, PhD Student

CTS-UNINOVA

NOVA School of Science and Technology | FCT NOVA

Department of Electrical and Computer Engineering

Campus FCT NOVA, 2829-516, Caparica, Portugal

shabnam.pasandide@uninova.pt 